\title{
A RETÓRICA DA PAISAGEM: UM INSTRUMENTO DE INTERPRETAÇÃO GEOGRÁFICA
}

- CAIO AUGUSTO AMORIM MACIEL'

\section{RESUMO}

DISCUTE-SE COMO A ABORDAGEM CULTURAL PODE CONTEMPLAR A PAISAGEM TANTO COMO UMA LEITURA SUBJETIVA DE MUNDO QUANTO UMA REALIDADE QUE TEM EXISTÊNCIA CONCRETA. NESTE TRABALHO, CONSIDERA-SE A PAISAGEM ENQUANTO PARTE DO PROCESSO DISCURSIVO DE ORDENAMENTO DA IMAGEM DO MUNDO A PARTIR DO AMBIENTE

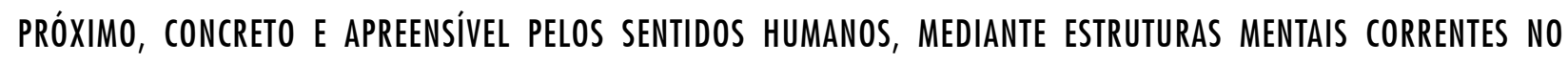
UNIVERSO SÓCIO-CULTURAL DE CADA POVO. ASSIM, PENSAR O ESPAÇO ATRAVÉS DA PAISAGEM PERMITIRIA AO SUJEITO UM SALTO ABSTRATO E NÃO ALEATÓRIO DESDE OS LUGARES IMEDIATOS DA EXISTÊNCIA ATÉ O DESCONHECIDO. DENOMINASE TAL HIPÓTESE DE PENSAMENTO METONÍMICO INTRÍNSECO ÀS REPRESENTACÕES GEOGRÁFICAS, CONSISTINDO EM QUE, INCITADOS A EXPRESSAR A INSERÇÃO DO COTIDIANO EM EXTENSÕES ESPACIAIS MAIS VASTAS OU VICE-VERSA, OS SUJEITOS MOBILIZARIAM UMA RAZÃO RETÓRICA PARA COMUNICAR COM FACILIDADE AQUILO QUE PERCEBEM COMO MAIS EVIDENTE E IMPORTANTE NAS PAISAGENS. COMO CAMPO EXPERIMENTAL DE ANÁLISE FORAM ESTUDADAS PAISAGENS ENUNCIADAS POR HABITANTES DO SEMI-ÁRIDO PERNAMBUCANO, DE MODO A AVALIAR O POTENCIAL EXPLICATIVO dO CONCEITO DE METONIMIA GEOGRÁFICA.

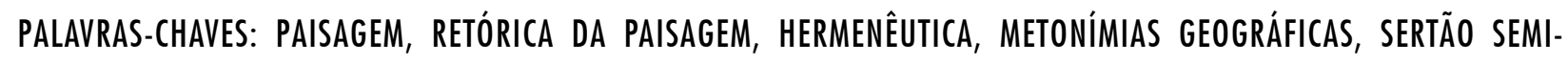
ÁRIDO.

A idéia de paisagem tem permanecido "um conceito-chave da Geografia" (CORRÊA e ROSENDAHL, 1998, p.8), a despeito das notáveis diferenças epistemológicas presentes na história do pensamento geográfico. Refletir sobre esse alicerce de nossa disciplina representa a atualizaçao de um debate filosófico primordial: de um lado defende-se a necessidade de descrição das conformações naturais e culturais do espaço; de outro define-se a paisagem eminentemente como repre- sentação subjetiva do olhar. Pode-se afirmar que tal encruzilhada permanece um dos problemas ontológicos maiores da geografia.

Como uma concordância ampla e imediata não é possível, nem talvez desejável, a paisagem pode ser compreendida, à guisa de orientar o debate, como um trabalho discursivo de ordenamento da imagem do mundo a partir do ambiente próximo, concreto e apreensível pelos sentidos humanos, mediante estruturas mentais correntes no univer- 
so sociocultural de cada época e de cada povo. Em correlação com estas "inscrições paradigmáticas", o trabalho articulador da cultura - enquanto atividade do sujeito sobre si mesmo - conferiria coerência às tensões entre os particularismos $\mathrm{e}$ universalismos que emergem em um dado lugar. Nas palavras inspiradoras de Paul Claval:

O que lemos no mundo e na sociedade é o que aprendemos a ver; nós o enunciamos nos termos que sabemos utilizar. Certas pessoas são mais observadoras e provam ter um espírito mais curioso: seu olhar percebe mais detalhes e revela configurações que escapam aos outros. Mas a maneira como o campo visual é varrido, como os sons são analisados e os perfumes rememorados traz a marca de contextos comuns. (CLAVAL, 1999, p. 81)

Coloca-se, então, uma questão fundamental para a geografia: como a abordagem cultural pode contemplar a paisagem tanto como uma leitura de mundo quanto como uma realidade que tem existência material, concreta, tal como é de nossa tradição acadêmica?

A unicidade da existência humana na face da Terra manifesta-se simbolicamente de infinitas maneiras. Mas a despeito de ser epifania (re-presentação), a paisagem liga-se de modo contundente às formas objetivas da natureza, ou seja, é fisionomia - e esta é a especificidade maior desta aparição ou emergência. Quer dizer, ela possui tanto uma dimensão palpável, presente no mundo exterior, quanto um componente de imaginação, todavia inextricavelmente correlacionados pela ação cultural dos indivíduos.
Assim sendo, a imaginação e o repertório do imaginário social e individual não deformam o olhar sobre o mundo, porque constituem uma totalidade que cria o sentido e a própria existência (DURAND, 1988), resolvendo as tensões entre individualidade e coletividade. As pessoas projetam dialeticamente seus sentimentos sobre a natureza, identificando correlações entre os aspectos materiais e suas pulsões interiores. Essa visão coaduna-se com a existência de um imaginário geográfico na origem das representações espaciais, o qual contribui para decifrar o sentido das ações humanas.

\section{PAISAGEM COMO MEIO DE COMPREENSÃO DO}

PENSAMENTO FIGURATIVO SOBRE O ESPAÇO

Sabe-se que as identidades territoriais - sejam pessoais ou coletivas - estão ligadas a um lugar de onde se mobiliza e reinterpreta uma dada tradição; quer dizer, é a partir de uma carga simbólica narrativamente referenciada nos espaços de vida que se constrói uma compreensão das conexões e recortes históricos, sociais e biográficos envolvidos em representações espaciais mais abrangentes.

É possível, portanto, sublinhar o papel das simbologias paisagísticas, uma vez que estas permitiriam ao sujeito um salto abstrato e não aleatório desde os espaços imediatos da existência até o alhures. Denominaremos tal hipótese de pensamento metonimico intrínseco às representações geográficas, consistindo em que, incitados a refletir e expressar a inserção do cotidiano em extensões espaciais mais vastas ou vice-versa, os sujeitos mobilizam uma razão retórica para comunicar com facilidade aquilo que percebem como mais evidente e importante. Enquanto se referem ao lugar, partem do radicalmen- 
te subjetivo, da consciência de si e até da corporeidade da existência; quando constroem paisagens, dialogam de preferência com aspectos culturais e políticos, recuperando uma memória coletiva, um arsenal de argumentos e um imaginário social corrente nos discursos da e sobre uma região.

O equilíbrio entre diferentes esferas da consciência espacial (do aqui-conbecido às terrae incognitae) é buscado através de um procedimento metafórico do pensar, onde o estabelecimento de relações entre os objetos geográficos ocupa uma posição fundamental na ordenação da diversidade e antecipação do desconhecido, embasando discursos culturalmente reconhecidos por sua coerência e plausibilidade. Por isto o imaginário geográfico, enquanto parte do processo de identidade territorial, não é de todo alienado das condições reais do terreno, e precisa pelo menos estar conformado com uma imaginação socialmente validada.

Quando se estuda o conceito de paisagem, percebe-se claramente que uma das mais fortes determinações semânticas da imaginação geográfica reside na seleção de alguns atributos da realidade, os quais são colocados em destaque, tomados como centrais ou, no limite, passam a designar por inteiro esta realidade a que se referem. Tal procedimento básico aponta justamente para a possibilidade de se considerar as paisagens enquanto metonímias geográficas, esquemas ou modelos antecipatórios acerca de uma realidade mais extensa.

Em que, do ponto de vista teórico, a analogia da paisagem com uma figura de retórica pode ser produtiva? Primeiro, porque a paisagem traduz a pretensão da geografia em condensar a diversidade do espaço em um discurso demonstrativo, intencionalmente descritivo, mas ao mesmo tempo sintético, focalizando temas representativos do Todo ou singularizadores de suas partes. Tal poder de correlacionar partes e todo é justamente o que caracteriza o procedimento metafórico denominado genericamente de metonímia ou, no caso particular de uma relação de pertencimento, de sinédoque.

E ainda, ao propor o estudo dos processos de simbolização que consubstanciam as paisagens, a geografia cultural concede àquela figura de retórica uma qualidade criativa que operaria através de um imaginário geográfico durante as tentativas dos habitantes em evocar um espaço mais abrangente e abstrato, de forma aproximativa. Dedicar-se à interpretação desses mecanismos significa adotar uma atitude hermenêutica.

O processo metonímico indicaria a direção do pensamento metafórico acionado para tentar conferir coerência ao espaço vivido, imprimir-lhe uma fisionomia esperada, que seria ajustada na medida do maior conhecimento do território e de suas qualidades ambientais. Neste sentido, seria somente a partir de sujeitos conscientes e ativos que os espaços figurados se enunciariam narrativamente enquanto estratégia de conhecimento e re-interpretação do mundo, adquirindo relevância para uma análise geográfica dos sentidos e valores atribuídos às paisagens pelos seus habitantes.

A emergência de uma paisagem como conhecimento descritivo de um certo espaço estaria carregada pelas tensões entre aquilo que o sujeito espera encontrar (antecipações metonímicas) e o crescente grau de diferenciação do universo ao seu redor. Portanto, haveria sempre na cognição paisagística um processo de ajustamento ou "equilibração", no sentido piagetiano, entre o previsto 
e o imprevisto na descoberta do mundo. De fato, o problema da tensão cognitiva decorrente da falta de um ajuste automático das nossas antecipações ao mundo tal como ele se nos vai sendo desvelado conduziu certos pensadores a uma abordagem interacionista do conhecimento. Segundo tal abordagem, toda interpretação baseia-se sempre no aprimoramento dos esquemas da realidade externa que são preconcebidos pelos sujeitos.

A idéia de que as re-interpretações do real refletiriam a permanente re-qualificação de nossas idéias apriorísticas pode ser bastante útil para entendermos o papel das figurações paisagísticas, ou melhor, da retórica da paisagem em geral. George F. Luger, analisando a contribuição do construtivismo do biólogo e psicólogo Jean Piaget sobre o problema da compreensão, aponta como há nesta corrente do pensamento uma certa interpenetração das tradições empiristas e racionalistas da ciência, partindo da premissa de que fenômenos externos somente podem ser assimilados de acordo com a nossa compreensão corrente, ao mesmo tempo em que é necessária uma acomodação da nossa compreensão às demandas do fenômeno: "Os construtivistas usam o termo esquema para descrever uma estrutura a priori usada para organizar a experiência do mundo externo. [...] Por este ponto de vista a observação não é passiva e neutra, mas sim ativa e interpretativa" (LUGER, 2004, p.724).

A investigação geográfica interessada na experiência e no discurso dos habitantes a partir de seus lugares de vida e nos sentidos que eles atribuem ao meio deve, igualmente, atentar para essas tensões cognitivas entre o esperado face ao percebido de fato, que fazem irromper uma paisagem. Resulta daí a insuficiência de somente catalogar imagens simbólicas que seriam mobilizadas para sublinhar um dado contorno territorial, como tem sido feito em muitos trabalhos. A paisagem é uma circunstância interpretada na medida em que resulta de um processo contínuo de ajustamento dos nossos "esquemas pertinentes do real" (representações da nossa inserção no mundo) ao conhecimento crescente deste mesmo real. Prossegue Luger na explanação do interacionismo e do construtivismo, cujas implicações para a idéia de razão metonímica da paisagem são flagrantes:

A informação percebida, o conbecimento a posteriori de Kant, nunca se ajusta precisamente nos nossos esquemas preconcebidos, a priori. Desta tensão, os vieses baseados em esquemas que o sujeito utiliza para organizar a experiência são modificados, expandidos ou substituídos. A necessidade de acomodação em face das interações malsucedidas com o ambiente provoca um processo de equilibração cognitiva. [...] Uma consedüência importante do construtivismo é que a interpretação de qualquer situação envolve a imposição dos conceitos, categorias e objetivos do observador. [...] A análise construtivista mostra que nenbuma experiência épossível sem o uso de algum esquema para organizar esta experiência. (LUGER, op. cit., p.724-725)

Piaget propôs, assim, uma abordagem inovadora à compreensão, alcunhando-a de epistemologia genética, que parte do princípio de que a falta de um ajuste perfeito dos esquemas mentais ao mundo real cria uma tensão cognitiva que somente é resolvida através de um processo incessante de 
revisão dos modelos pré-concebidos. Fica clara a distância em relação a uma percepção puramente fenomenológica, isto é, livre de pressupostos, conceitos e vieses, dada a importância da linguagem. $\mathrm{Na}$ concepção piagetiana, as permanentes atualizações dos nossos preconceitos, previsões e antecipações explicam a tendência da compreensão à "equilibração", ainda conforme Luger:

A revisão de esquemas e o movimento em direção à equilibração é uma predisposição genética e uma acomodação às estruturas da sociedade e ao mundo externo. Ela combina estas duas forças e representa uma predisposição incorporada para a sobrevivência. A modificação de esquemas é uma função tanto a priori da nossa genética como a posteriori da sociedade e do mundo; ela é o produto de nossa existência no espaço e no tempo, ou seja, de nossa corporificação. (Id. Ibid.) [grifo nosso]

Que contribuições efetivas o interacionismo pode trazer à retórica da paisagem? Tomada a partir das premissas acima, a retórica em geral - e a metonímia geográfica em particular - não deve ser entendida como um recurso artificial de persuasão, ou apenas enquanto uso de imagens lexicalizadas para influir no ato comunicativo; ela comporta também um aspecto da racionalidade metafórica orientada pela imaginação, mas que visa a chegar a um conhecimento do mundo exterior mediante sucessivas revisões e acomodações. Existem muitos modelos diferentes da realidade, vários podem ser tidos como verossímeis, mas nem todos têm a mesma aceitação social.
A situação retórica supõe tanto tensão quanto cooperação entre interlocutores, os quais situam seus discursos em relação ao que é esperado, crível (lógica do provável) e portanto submetido em certa medida às regularidades reconhecidas de parte a parte. Falar através da paisagem é colocar a dialética conhecido-desconhecido no centro do horizonte noótico daqueles que são seus narradores, mas que lançam mão de uma argumentação modelizadora a partir da qual se deseja atingir uma adesão negociada dos interlocutores.

\section{O ELOQUENTE ESPETÁCULO DA PAISAGEM}

A criatividade do discurso paisagístico está, desta maneira, profundamente apoiada em ligações e dissociações constatáveis na estrutura do real, muito embora os dados da realidade possam ser construtos imaginários e carregados de subjetividade. As metonímias e sinédoques, como relações de associação dadas no interior de uma tradiçãodestino, se baseiam em laços de contiguidade e conexão entre objetos, tomando parte de um tipo de raciocínio e argumentação que emerge de domínios bem conhecidos e aceitos (mitos, história, fisionomia geográfica memorável etc). Elas podem assumir a solidez de provas, de demonstração de uma visão de mundo.

A paisagem cultural é uma tribuna de onde os sujeitos falam de sua cosmovisão sob o prisma dos espaços conhecidos, tentando encontrar a especificidade do seu lugar de vida num quadro maior. Simetricamente, o discurso pode percorrer o itinerário oposto e é preciso admitir que o peso dos estereótipos atua frequentemente em ambos os níveis, incitando as pessoas a encontrar adaptações coerentes para os lapsos entre identidades 
territoriais imediatas e "estranhas". No domínio da estetização da vida, a paisagem vem a ser concebida como teatro da memória: projeto onde se coloca em cena, visual e figurativamente, um conjunto de conhecimentos geográficos individuais e coletivos. Monta-se tal como um "espetáculo" ou re-presentação de uma fisionomia cujos equivalentes existem empiricamente, mas que estão ali apenas vertidos, transfigurados intencionalmente para demonstrar e descrever a realidade de modo esquemático.

Por outro lado, os quadros resultantes deste processo de encenação do fato do mundo têm a força de exemplos organizadores da subjetividade: na qualidade de imaginário, linguagem e teatro eles são processos sociais de estruturação efetiva do espaço. E se há a intenção de concatenar um discurso identitário por intermédio da encenação, há também um ethos que condicionará o seu rosto. O sujeito que enuncia esta visão culturalmente centrada de mundo agirá sobre estruturas morais e políticas préestabelecidas, tentando atingir o mais profundamente o caráter da audiência a que se reporta - seja para entrar em acordo ou seduzir, seja para demarcar uma atitude de diferenciação ou mesmo de apartação.

De um modo geral, as imagens são recursos poderosos da descrição, e a retórica da paisagem está cheia delas. Deve-se atentar ao problema de que no âmago da retórica está o desejo de fazer ver e que o sentido da visão é um dos preponderantes em nossa sociedade. Depreende-se daí que a descrição assume na geografia o papel de uma figura central, para a qual e pela qual se ordenam todas as demais formas do pensamento figurado.
A passagem do visível ao inteligível necessita de uma multiplicidade de procedimentos associativos que personifiquem aquilo que queremos reter e transmitir da realidade: imagens, formas, símbolos, representações. Esta materialização de imagens em lugares e vice-versa será tão mais verdadeira na medida em que ela se apóie associativamente na força da visão: como já afirmava Quintiliano, "é muito vantajoso juntar à verdade um quadro plausível dos fatos, que dê aos ouvintes a impressão de que eles assistem, por assim dizer, à cena" (QUINTILIEN, Institution oratoire apud GARDESTAMINE, 1996, p.41).

As representações espaciais pressupõem a escolha e conexão de características específicas e genéricas como fiéis a uma realidade geográfica mais complexa, mesmo que puramente imaginada ou esquemática, visando a um quadro inteligível que transforme o caos em ordem reconhecível, assimilável. Em consequência, não é possível, pelo menos numa abordagem etnogeográfica, prescindir desses processos de "focalização" e "concentração" simbólica em atributos mais palpáveis, uma vez que eles fariam parte dos mecanismos antecipatórios que os sujeitos utilizam para organizar suas experiências do espaço.

Evidentemente as conformações do imaginário expressam-se em outras tantas figuras de linguagem e pensamento que recorrem a uma razão metafórica e legendária; entretanto, deve-se sublinhar que a escolha das metonímias decorre da sua relação direta com a necessidade de condensar e transmitir um conhecimento espacial tal como as paisagens. As paisagens-metonímias, enquanto instrumentos de análise, permitem conhecer como se constrói e equilibra o olhar no trânsito entre: 
a) o lugar, base da vida cotidiana; $b$ ) uma ou mais regiões culturais, até as fronteiras crescentemente difusas dos territórios que encarnam sentimentos de pertença e, por fim, c) o mundo afora, ou seja, as ainda mais "distantes", mal conhecidas e anônimas terras ignotas.

\section{A ABORDAGEM HERMENÊUTICA DA PAISAGEM: EM BUSCA}

DA RACIONALIDADE NARRATIVO-INTERPRETATIVA

Metonímias geográficas seriam, enfim, mapas provisórios que falam sobre o estado da arte geosófica de um povo ou qualquer grupo social, como esquemas que estão ao mesmo tempo em permanente revisão, almejando adequar-se ao real e compreendê-lo (ver Figura 1 - Esquema de análise hermenêutica da retórica da paisagem). Tal compreensão deve ser vista enquanto uma interação com o mundo, pois "o que percebemos é mediado pelo que esperamos; o que esperamos é influenciado pelo que é percebido: isto é, essas duas funções podem ser entendidas apenas em termos uma da outra" (LUGER, 2004, p.725).

O desenvolvimento de um conhecimento geográfico prático (concreto ou imaginário) alimentase de narrativas e figurações espaciais inclusivas ou excludentes, concebendo-se os diversos níveis da existência num mosaico imperfeito que materializa a consciência, a imaginação e a vivência progressiva do meio por seus habitantes. Trata-se, a um só tempo, de uma intuição e de uma cognição espacial carregada de idiossincrasias, mas que é também resultante de um esforço cotidiano e coletivo em esboçar a realidade do mundo a partir da ação cultural, isto é, sem dispensar pontos de referência constituídos por sistemas de crenças e espaços menos provincianos, nos quais o sujeito tenta situar o imediato.

Figura 1 - Modelo da ANÁlise Hermenêutica da ReTórica DA PAISAGEM

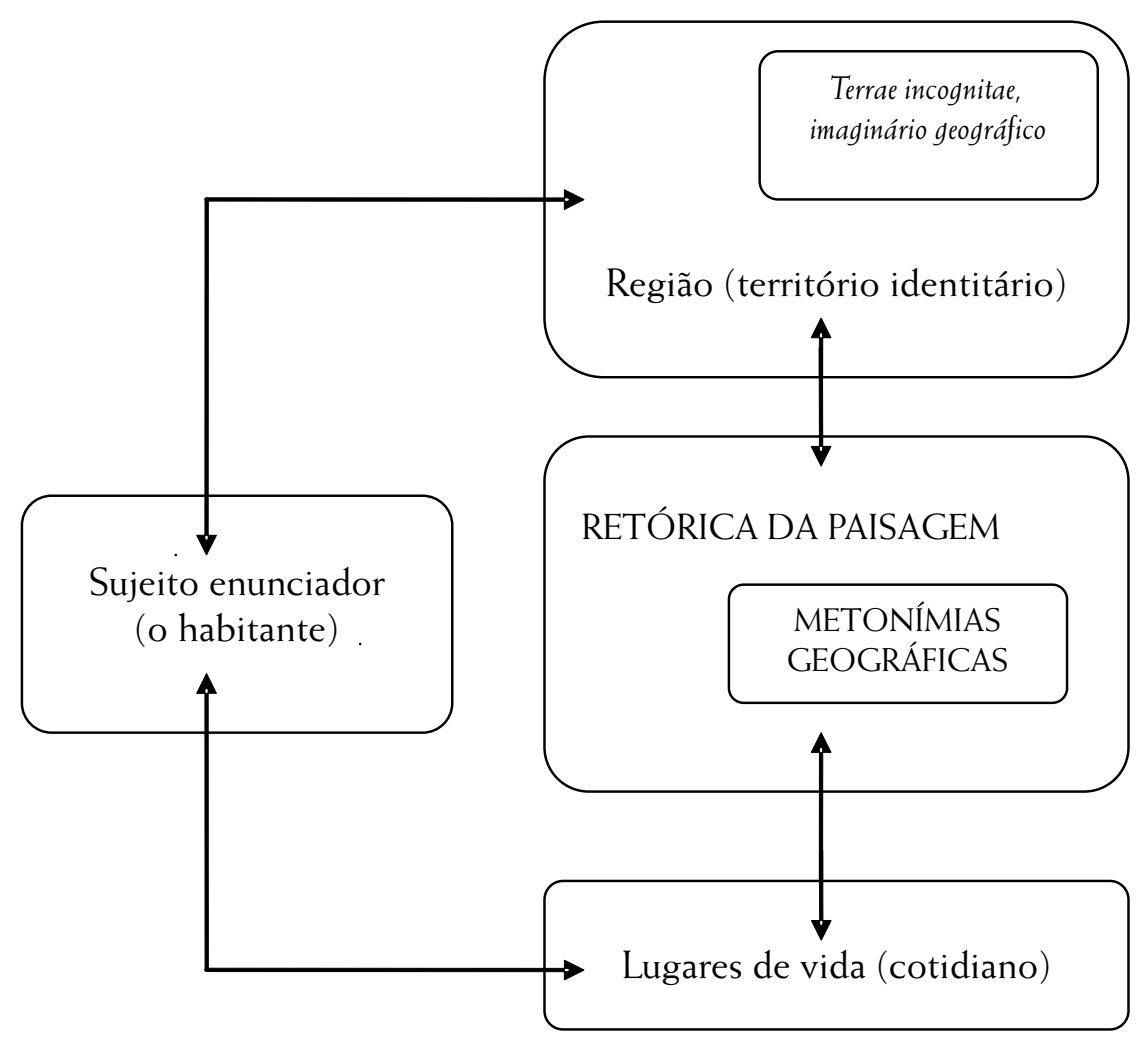


A hermenêutica sugere que se possa interpretar como essa tensão básica impregna o conceito de paisagem de significados e intenções a partir das formas figuradas do pensamento, isto é, do recurso a uma retórica que lhe é intrínseca.

O processo metonímico, alcançando no limite da opacidade do inexplorado, guarda a rationale do imaginário geográfico e somente pode ser entendido como uma função antecipatória inerente ao pensamento, necessária à apreensão e compreensão do mundo. Pode-se recorrer a Gadamer (1998, p.400-427) para enquadrar a questão dos preconceitos como fato inerente à experiência hermenêutica, ou seja, como uma condição mesma para a compreensão. É preciso, entretanto, separar o preconceito que permite o conhecimento (compreensão antecipatória) do preconceito que impede ou tolhe a capacidade de pensar. Neste último caso, trata-se de uma violência que se exerce no nível do pensamento, ato invisível de realizar projeções no cotidiano e que torna o sujeito "impermeável à prova da realidade", como dizem os psicanalistas (LANDA, 1998, p.73-75).

As abreviações das experiências vividas fazem parte do arsenal de procedimentos heurísticos que permitem às pessoas conhecer o mundo e o outro, integrando - mesmo que provisoriamente - os objetos novos que vão aparecendo fragmentariamente no cotidiano da existência num sistema coerente. Na sua experiência de espaço, a humanidade precisa lançar mão destas reduções, o que não significa dizer que as metonímias geográficas restringem-se a abreviaturas esquemáticas - elas são meros instrumentos de busca de um real simultaneamente vivido e imaginado. O estudo do senso comum, das ideias feitas sobre as regiões e de- mais estigmas espaciais, é bastante fértil na geografia humana a título de desvendar identidades territoriais; porém - infelizmente - isto tem sido feito em detrimento de uma atenção mais detida no papel positivo dos modelos mentais. Em resumo, na perspectiva da interação, a metonímia paisagística deve ser vista como um ato cognitivo e não meramente reprodutivo.

A RETÓRICA A SERVIÇO DA INTERPRETAÇÃO GEOGRÁFICA: TENTATIVA DE APLICAÇÃO PRÁTICA

A paisagem, enfim, é uma noção necessária à compreensão dos mecanismos de produção do imaginário geográfico que subentendem as ações concretas sobre diversos recortes territoriais e sobre o ambiente. Mais precisamente, a retórica da paisagem revela, a partir de lugares com forte capacidade de síntese, as ligações específicas que os homens mantêm com o meio. A evocação de paisagens metonímicas parece indicar a aliança social estabelecida em torno de um modo de vida, de um ambiente, de um território.

Em exercício recente, algumas paisagens enunciadas por habitantes do semi-árido pernambucano foram por mim estudadas em três recortes espaciais, de modo a avaliar o potencial explicativo do conceito de metonímia geográfica (MACIEL, 2004). O ponto de partida foram as narrativas sobre o semi-árido nordestino a partir dos argumentos contundentes mobilizados pelos seus próprios habitantes, considerando que para atingir o patamar de evidência paradigmática, as figurações paisagísticas precisariam do enquadramento em outros modelos de apreensão e compreensão do mundo. Nesse estudo de caso foram interpretadas algumas metonímias geográficas utilizadas pelos 
sujeitos para definir, a partir de seus lugares de vida, as identidades territoriais do Agreste de Caruaru, do Sertão do Pajeú e do Sertão do São Francisco, recortes experimentais selecionados.

Foram recolhidos cem depoimentos de agricultores e pessoas relacionadas ao meio rural em seus locais de vida, visando a levantar como eles descreviam o espaço do entorno, da região e das áreas mais distantes, procedendo-se à identificação, interpretação e classificação dos instrumentos retóricos mobilizados. Este caminho foi tentado como uma opção válida para investigar como e por que algumas paisagens do semi-árido pernambucano, a despeito de sua variabilidade, assumem um caráter simbólico de condensação, que ali é profundamente relacionado com a idéia de sertão e de ruralidade (ver Figura 2).

FIGURA 2 - RESUMO DA INSTITUIÇÃO SIMBÓLICA DE TRÊS ENQUADRAMENTOS NO SEMI-ÁRIDO PERNAMBUCANO A PARTIR DE QUATRO ELEMENTOS RETÓRICOS E SUA RELAÇÃO COM A IDEIA SUBJACENTE DE SERTÃO

\begin{tabular}{|c|c|c|c|}
\hline & Agreste de Caruaru & Sertão do Pajeú & Sertão do São Francisco \\
\hline $\begin{array}{l}\text { 1. Especificidades do } \\
\text { imaginário da } \\
\text { natureza }\end{array}$ & $\begin{array}{l}\text { Semi-árido moderado; } \\
\text { anfibologia de sítio e } \\
\text { posição; proximidade } \\
\text { da costa úmida; a seca } \\
\text { como problema urbano; } \\
\text { diversidade de paisagens }\end{array}$ & $\begin{array}{l}\text { Semi-árido rústico típico; } \\
\text { convivência com a seca } \\
\text { (adaptabilidade do homem } \\
\text { ao meio); o vale do alto } \\
\text { Pajeú seria um "pays" de } \\
\text { Estética dura e bravia }\end{array}$ & $\begin{array}{l}\text { Semi-árido acentuado, mas } \\
\text { transformado pela ação } \\
\text { humana; superação da seca; } \\
\text { livre vocação agrícola via } \\
\text { irrigação; beleza gerada pelo } \\
\text { artefato (pragmática) }\end{array}$ \\
\hline $\begin{array}{l}\text { 2. Figuras de retórica } \\
\text { usadas na } \\
\text { caracterização }\end{array}$ & $\begin{array}{l}\text { Ambiguidade de auto- } \\
\text { definição; deserto no } \\
\text { passado; Hipotipose: } \\
\text { jogo entre dois fundos } \\
\text { materiais igualmente } \\
\text { adaptáveis; argumentos } \\
\text { de síntese. }\end{array}$ & $\begin{array}{l}\text { Contra a metáfora do } \\
\text { deserto; metáfora do oásis; }_{i} \\
\text { exemplaridade (sertão } \\
\text { ideal / tradicional) } \\
\text { argumentos de tipicidade e } \\
\text { de autenticidade. }\end{array}$ & $\begin{array}{l}\text { Metáforas do deserto/oásis e } \\
\text { do jardim; antítese do sertão } \\
\text { seco; mito do eldorado; } \\
\text { hipérbole das águas; } \\
\text { argumentos de novidade e de } \\
\text { progresso técnico }\end{array}$ \\
\hline $\begin{array}{l}\text { 3. Paisagens } \\
\text { metonímicas e } \\
\text { imagens } \\
\text { simbólicas } \\
\text { associadas }\end{array}$ & $\begin{array}{l}\text { A cidade de Caruaru, a } \\
\text { feira e seu comércio; as } \\
\text { festividades juninas; o rio } \\
\text { Ipojuca; o planalto da } \\
\text { Borborema e suas serras } \\
\text { locais (brejos); a rodovia } \\
\text { BR-232 }\end{array}$ & $\begin{array}{l}\text { Pequena produção e } \\
\text { pequenas propriedades; } \\
\text { elevada densidade de } \\
\text { ocupação e rede de } \\
\text { cidades com Afogados da } \\
\text { Ingazeira no centro; os } \\
\text { sindicatos; o rio Pajeú }\end{array}$ & $\begin{array}{l}\text { O rio São Francisco, o verde } \\
\text { perene dos perímetros de } \\
\text { irrigação, as lavouras } \\
\text { intensivas (destaque para a } \\
\text { vitivinicultura); a cidade de } \\
\text { Petrolina, as hidrelétricas; a } \\
\text { maconha nas áreas isoladas. }\end{array}$ \\
\hline $\begin{array}{l}\text { 4. Valores e } \\
\text { sentimentos } \\
\text { dominantes }\end{array}$ & $\begin{array}{l}\text { Amálgama impreciso de } \\
\text { características advindas do } \\
\text { interior/sertão e da capital } \\
\text { (Recife); cultura sertaneja, } \\
\text { mas com estilo de vida } \\
\text { cosmopolita; urbanização. }\end{array}$ & $\begin{array}{l}\text { O mais típico e autêntico } \\
\text { sertão; organização e ação } \\
\text { para conviver com a seca e } \\
\text { o semi-árido; espaço de } \\
\text { resistência do modo de } \\
\text { vida rural tradicional, mas } \\
\text { não arcaico. }\end{array}$ & $\begin{array}{l}\text { Vitória da técnica sobre uma } \\
\text { natureza hostil, esta sendo } \\
\text { revertida por aquela em } \\
\text { potencialidade } \\
\text { espaço rural moderno e } \\
\text { inserido na globalização; } \\
\text { ideologia do progresso. }\end{array}$ \\
\hline Ideia de sertão & SERTÃO URBANIZADO & SERTÃO AUTÊNTICO & SERTÃO MODERNIZADO \\
\hline
\end{tabular}

FONTE: TRABALHO DE CAMPO COM A REALIZAÇÃO DE 100 ENTREVISTAS ENTRE JANEIRO E JULHO DE 2003 
Do mesmo modo, houve a preocupação em mostrar que, quando as paisagens não assumem tal papel identitário, os seus outros sentidos devem ser vistos como o estabelecimento e enunciação de novos consensos, vivências diversas, participando de uma batalha argumentativa acerca da região estudada. A título ilustrativo, se a idéia de Caruaru como sertão remete na prática a um não-sertão, posto que urbanizado, próximo e com a natureza dominada pela ação humana, isto não significa a inexistência de outras imagens consensuais retoricamente cristalizadas em paisagens simbólicas que são muitas vezes conflitantes com as interpretações dominantes. O mesmo pode ser dito dos outros recortes, resultando numa interessante contraposição de discursos.

Desta maneira, foi possível testar a eficácia semântica e comunicativa das metonímias paisagísticas, as quais possibilitaram a integração e conexão de tempos e espaços diversos em torno do semiárido e da permanente re-atualização de seus conteúdos. O reconhecimento, na prática, da existência e da importância simbólica dessas metonímias geográficas permitiu o aprofundamento das ligações entre o campo da retórica e do imaginário.

\section{RAZÃO METONÍMICA EM TRÊS RECORTES DA PAISAGEM NO} SEMI-ÁRIDO PERNAMBUCANO

Não cabe aprofundar nas linhas deste artigo uma análise de cunho comparativo. Todavia é importante sublinhar como a imagem geral de sertão é construída transversalmente nas três diferentes perspectivas em foco, sem a pretensão de esgotar o tema. Uma primeira observação é incontornável: a metáfora do deserto está presente em todas as representações vistas, seja numa vertente de adesão aos seus traços e simbolismos, seja para renegá-los.

Assim, para a grande maioria dos entrevistados, o espaço sertanejo continua a ser imaginado como selvagem ou semi-domesticado, desértico (árido e vazio), além de isolado pelas grandes distâncias ou pelas dificuldades de acesso. O sertão admitiria a conotação seja de uma fronteira ainda em conquista, seja de uma terra estranha, desconhecida, que se encontra "sempre mais para adiante" (depoimento de um agricultor caruaruense).

Essa caracterização quase mítica de um espaço imaginário evidentemente herdado da colonização é nuançada pela forma como os habitantes percebem a fisionomia do território sertanejo nos seus respectivos espaços de vida, quer dizer, a partir da interação entre o mito e a materialidade da existência. Existe um sertão metafórico culturalmente assimilado e um outro espaço, mais à vista, que é o sertão conhecido e experienciado na prática, um território inscrito pelas vivências de cada indivíduo. É por esta razão que a geografia existencial sertaneja baseada na figura primordial do deserto desdobra-se em interpretações que podem ser bastante diferenciadas.

Então, cruzando as diferentes concepções de sertão utilizadas direta ou indiretamente na enunciação de paisagens metonímicas pelos entrevistados em Caruaru, no Pajeú e no São Francisco, chegou-se à identificação de cinco grandes constelações do imaginário sertanejo que consistem em modos singulares de descrever e valorizar o semiárido pernambucano - embora possam se sobrepor em algumas de suas linhas argumentativas. Segue-se, então, uma caracterização sumária desses troncos do imaginário, apenas a título de facilitar 
a correlação com as principais paisagens mobilizadas nos eixos retóricos acima referidos; tais matrizes do pensamento metafórico estão ordenadas de acordo com um grau decrescente do recurso à simbologia-chave do deserto (ver Figura 3).

Dentro do regime escópico amplo e generalizado do deserto, aqueles que "transcrevem" quase que literalmente o mito do espaço incivilizado, inóspito e isolado para as paisagens metonímicas do sertão representam ainda um percentual bastante elevado de depoentes, chegando a $18 \%$ do total (Eixo I do imaginário de sertão).

Este sertão arquetípico, selvagem e ressecado não se fez presente, pelo menos isoladamente, como uma metonímia válida para a totalidade do São Francisco, justamente uma das zonas mais rústicas do semi-árido pernambucano, mas sob influência marcante da "miragem" do grande rio e da tecnologia de irrigação. Encontrando modesto eco no Pajeú, revela-se uma visão quase que essencialmente agrestina - mais próxima da "civilização" - através da qual as características sertanejas tendem a ser exacerbadas para demarcar uma apartação natural entre as regiões ou a fim de exprimir diferenças de ocupação e modo de vida. De uma maneira geral, podese então dizer que a abreviatura do espaço sertanejo a um deserto recebe forte influência dos estereótipos existentes na sociedade brasileira sobre o semiárido, notadamente nos meios urbanos.
O segundo bloco do imaginário sertanejo (Eixo II) utiliza as imagens de uma região desértica para realçar seus espaços de exceção natural (beira-rio, serras úmidas como oásis) ou construídos pelo homem (através da irrigação, de técnicas adaptadas ao meio e de ações coletivas). Se considerarmos que nesta outra matriz da imaginação a metáfora do deserto tem papel e força quase que idênticos ao primeiro caso (afinal, que é o imaginário do oásis senão uma outra faceta desse mesmo geosímbolo?), chega-se a nada menos que à metade dos relatos produzidos pelos entrevistados (Eixos do imaginário de sertão I e II = 50\%).

Estamos aqui diante do poderoso mito da natureza hostil, que se desdobra na emergência de vários tipos de geografia existencial: em primeiro lugar, delineia-se uma forte aversão à região sertaneja semi-árida, que assume o aspecto de um espaço da repulsa, povoado por figurações negativas (paisagens metonímicas da fome, aridez, miséria, vazio etc). Semelhante tipo de interpretação mostrouse mais presente no São Francisco e no Agreste, sendo menos evidente no Pajeú. Em segundo lugar, aparece a relativização dessas cenas grotescas, que, sem serem negadas, são postas lado a lado com imagens positivas de um passado idealizado ou da experiência biográfica (a fazenda, a cultura, o vaqueiro, a família etc), de modo a construir o sertão como espaço da nostalgia. 


\begin{tabular}{|c|c|c|}
\hline RETÓRICA DA PAISAGEM E IMAGINÁRIO DE SERTÃO & Recortes & Freqüência \\
\hline $\begin{array}{l}\text { Eixo I - Abreviatura quase literal à metáfora do deserto: vazio, árido, espaço } \\
\text { incivilizado, fronteira, ruralidade profunda, homem rude, sob domínio } \\
\text { permanente da seca. Reforço, por contraste, do paradigma hídrico } \\
\text { (sobretudo da irrigação como panacéia). }\end{array}$ & $\begin{array}{l}\text { Agreste e } \\
\text { Pajeú }\end{array}$ & $18 \%$ \\
\hline $\begin{array}{l}\text { Eixo II - Metáfora do deserto cotejada pela metáfora do oásis: espaços } \\
\text { naturais menos secos e/ou poder da técnica (irrigação) e da ação organizada } \\
\text { do homem (política) transformando o meio e rompendo o tradicionalismo. }\end{array}$ & $\begin{array}{c}\text { Pajeú e } \\
\text { São Francisco }\end{array}$ & $32 \%$ \\
\hline $\begin{array}{l}\text { Eixo III - Atenuação da metáfora do deserto: espaço árido e distante em } \\
\text { modernização, com potencialidades naturais e humanas variadas; poder da } \\
\text { técnica (irrigação), da urbanização, ou da ação organizada do homem } \\
\text { (política) }\end{array}$ & Agreste & $20 \%$ \\
\hline $\begin{array}{l}\text { Eixo IV - Normalidade da semi-aridez, uso restrito da metáfora do deserto; } \\
\text { espaço rústico que oferece possibilidade de "convivência" dependendo da } \\
\text { ação humana (conhecimentos, técnicas variadas, política) }\end{array}$ & $\begin{array}{c}\text { Pajeú e } \\
\text { São Francisco }\end{array}$ & $21 \%$ \\
\hline $\begin{array}{l}\text { Eixo V - Normalidade da semi-aridez (convivência), com uso restrito da } \\
\text { metáfora do deserto e do oásis (áreas de exceção) em função de variações } \\
\text { naturais (brejos, beira-rio) e/ou humanas (técnicas, sobretudo irrigação) }\end{array}$ & São Francisco & $9 \%$ \\
\hline & Total & $100 \%$ \\
\hline
\end{tabular}

FONTE: TRABALHO DE CAMPO COM A REALIZAÇÃO DE 100 ENTREVISTAS ENTRE JANEIRO E JULHO DE 2003

Uma variante do espaço da repulsa é representada pelas pessoas que imaginam o sertão desértico e vazio como resultado do abandono e da desmobilização de seus próprios habitantes, que seriam fatalistas e desorganizados, neste caso, a sensação de desamparo imputa aos homens a responsabilidade por não se estabelecer uma relação mais equilibrada com a natureza, sendo um discurso originário do Pajeú, um sertão marcado pela ação política dos pequenos proprietários, sindicatos rurais e organizações não-governamentais (ONG's).

Por fim, ainda a partir do Pajeú, observa-se que os indivíduos que o concebem como um sertão favorecido, mais ameno e "humano", projetam sobre seus espaços de vida paisagens fundadas na idéia de oásis, ou seja, também pensam as zonas serta- nejas circunvizinhas como selvagens, inabitáveis e rudes, mobilizando sobre elas muitos dos clichês negativos que se aplicam normalmente ao semi-árido. O sertão são os outros...

Como quer que seja, é interessante registrar que para grande parte dos que mobilizam enfaticamente o imaginário do deserto é de praxe emendar, logo em seguida, que o sertão consiste num território em processo de modernização, apresentando melhorias significativas e oportunidades promissoras de desenvolvimento. Invariavelmente a irrigação aparece como o indicador dessa mudança, havendo uma tensão entre o imaginário da natureza e a idéia de redenção técnica, de ação humana transformando o meio. Aqui o sentimento predominante é o de que o sertão, antes ruim, 
horrível, inabitável, agora está ficando bom, devido às inúmeras obras hídricas e à agricultura irrigada - decerto sob a influência da publicidade das ações governamentais (adutoras, transposição/revitalização do São Francisco, irrigação etc).

O terceiro tipo de imaginário de sertão (Eixo III), proferido a partir do universo agrestino, também se soma ao cabedal de idéias que admitem um processo de modernização em curso no território semi-árido, incluindo plenamente o agreste como seu partícipe. Diferentemente dos dois primeiros eixos, surge aqui uma ênfase maior na urbanização, muito embora o imaginário da irrigação continue se fazendo presente. A metáfora do deserto é aí deslocada para um passado mais ou menos distante, sendo a própria experiência do agreste o modelo de civilização que, paulatinamente, penetraria e colonizaria a fronteira sertaneja. Por isto, reduz-se o papel da imagem do deserto a uma força de expressão propriamente dita, sem correspondência rigorosa com a estrutura do real. Além do mais, a velocidade das mudanças engendra um forte sentimento de nostalgia de um "sertão autêntico" que vai sendo pouco a pouco assimilado pela modernidade, quando não "folclorizado" nas festas juninas.

Enfim, o que nos parece mais importante a frisar é que, tomando-se os dois últimos discursos calcados com ênfase variável na metáfora do deserto (Eixos II e III), percebe-se que, para metade das pessoas inquiridas ao longo da pesquisa (52\%), o sertão é um território que apresenta, sim, problemas relacionados à dificuldade de convivência do homem com o ambiente semi-árido, mas que ao mesmo tempo guarda variadas potencialidades que podem e estão sendo aproveitadas no presen- te, de modo a apontar um futuro positivo para a região. Isto é ainda mais forte nas posturas que tomam a semi-aridez como uma condição absolutamente normal do território sertanejo, relegando o imaginário do deserto e suas figurações negativas a um papel secundário na conformação da região.

De fato, existe uma matriz do imaginário sertanejo (o Eixo IV) em que o semi-árido é visto como um território rústico, porém plenamente passível de oferecer condições dignas para a existência humana, desde que haja a aplicação de tecnologias apropriadas num contexto social mais justo e democrático. Procurando diminuir ou circunstanciar aquelas figurações metonímicas escatológicas que são normalmente imputadas à região, este modo de ver o sertão apela para os signos provenientes dos modos de vida e das estratégias produtivas e organizacionais que ofereceriam alternativas para a sustentabilidade ambiental das explorações agrícolas no trópico seco.

Esses depoimentos depositam maior relevância não apenas na tecnologia em si, mas na organização da sociedade como o fator de apropriação adequada do espaço e de modernização de suas formas de exploração. O sertão continua a ser visto como um meio de grande rusticidade, sobretudo quanto à escassez de água, mas não é tão enquadrado como um deserto improdutivo, preferindo-se ressaltar suas potencialidades variáveis e as diversas maneiras pelas quais a sociedade pode adaptar-se à semi-aridez. O discurso da convivência surge com mais destaque dentre os habitantes do Pajeú, seguido por pessoas residentes no São Francisco, não sendo registrado no Agreste de Caruaru (talvez aí refletindo a perda relativa de importância da agricultura na economia). 
Poderia-se arguir que tal opinião implica uma postura romântica e idealista acerca das relações homem-natureza, mas é importante destacar que para mais de um quinto de todos os entrevistados a irrigação, afinal de contas, não aparece como o único caminho possível para superar os quadros de baixo nível de desenvolvimento econômico e atraso técnico comumente verificados no sertão. Isto é muito importante se levarmos em consideração que ultimamente a agricultura irrigada transformou-se numa mitologia quase tão poderosa quanto o imaginário trágico da seca. A modernidade, segundo essa visão que desmistifica o "sertão da água", estaria antes relacionada a um conjunto diversificado de ações políticas e inovações tecnológicas visando a aprimorar a "convivência" do homem com o semi-árido e as estiagens.

O território sertanejo, admitido decerto como um espaço de risco por suas qualidades ambientais imanentes, afasta-se tanto daquelas visões bizarras e chocantes de um deserto esturricado quanto do cenário de uma zona que deve ser inexoravelmente "ajardinada" pela panacéia da irrigação. Quer dizer, a correlação maniqueísta segundo a qual o sequeiro seria igual a atraso/obsolescência e a agricultura irrigada corresponderia a progresso/inovação é, enfim, quebrada. Torna-se melhor falar, por conseguinte, num sertão que nem está fadado à civilização, tampouco quer fechar-se em idealizações românticas de seus gêneros de vida.

O fato de o imaginário em questão ter sido enunciado preferencialmente a partir do Pajeú relaciona-se à incorporação, pelos sertanejos, do "discurso da convivência" aí amplamente disseminado através da rede de mediadores das organizações não-governamentais e outras entidades da sociedade civil, como igrejas, sindicatos, universidades ou órgãos de governo. Quer dizer, consiste num eco de posturas técnicas e políticas que trabalham com base em idéias como desenvolvimento sustentável, participação popular e associativismo. Trata-se de indício importante acerca dos novos discursos que estão surgindo para além da imagem trágica da região, merecendo registro para estudos posteriores.

Por último, observa-se no Eixo $\mathrm{V}$ que ocorre um outro tipo pensamento onde o sertão é ora contraído aos espaços imediatos de vida dos sertanejos, ora ao conjunto diversificado de microambientes que caracterizam uma região bastante diversificada do ponto de vista natural e humano (beira-rio, caatingas, serras, projetos etc). A metáfora do deserto pode ser aplicada ao alhures ou aos espaços mais secos, perdendo, porém, o seu caráter de evidência organizadora das visões de mundo, atenuada pela compreensão de que a aridez do sertão é algo dado, uma evidência da realidade, coisa normal.

Aparecem aqui, ainda, casos em que o sertanejo imagina o seu sertão como uma ilha de bonança, um espaço privilegiado pela natureza (com ou sem a ajuda da irrigação) e onde as figurações negativas de uma terra selvagem e ingrata não se encontram tão presentes nos seus discursos. Também se incorporam experiências biográficas relacionadas aos diferentes tipos de terreno. É bem verdade que apenas 9\% dos entrevistados demonstraram tal "abertura do olhar", mas não deixa de ser interessante constatar como podem ser valorizados certos elementos da paisagem que em outros contextos culturais são tomados em sentido inverso. 
CONSIDERAÇÕES FINAIS: A RETÓRICA DA PAISAGEM ESTÁ EM TODA PARTE

O recurso à análise do poder criativo da comunicação, que transforma imagem em linguagem, permite penetrar nos códigos de pensamento e processos de simbolização inerentes à paisagem, de modo a compreender como as pessoas constroem permanentemente suas geosofias, suas antecipações metonímicas do espaço - e como os grupos sociais entram em acordo sobre isso. As diferentes noções de sertão aqui estudadas refletem como essas acomodações de olhares subjetivos entram num processo de negociação cultural.

Os mesmos esquemas simbólicos largamente aceitos não resultam de modo automático em interpretações essenciais da realidade; ao invés disso, o cotejamento de horizontes hermenêuticos constrói novas significações, referências e evidências, incitando a busca por uma melhor aproximação com o real. Os lugares-comuns sobre o sertão não servem apenas para facilitar o discurso: sua generalidade consensual é o primeiro terreno da fusão de horizontes demarcado no seio de uma comunidade cultural que reage dinamicamente aos argumentos discrepantes.

A partir de um mesmo topos há uma gama de especulações possíveis, somente refreada pelos paradigmas socialmente acordados, que permanecem dominantes. Assim, a afirmação "o sertão é mais longe que o agreste" suscita que a metáfora da fronteira adquira um ar perfeitamente razoável para alguns agrestinos, mas não para outros, como aqueles que não percebem a diferença entre esses espaços em termos de distância, e sim de qualidades ambientais - "o sertão é mais seco que o agreste" aciona a metáfora do deserto; já o pensamento de que "o sertão e o agreste são uma coisa só", representa uma metonímia de tipo sinedóquico.

As figuras mobilizadas para forjar narrativas a partir dos topoi mais aceitos não se restringem a ornamentos, integrando de preferência argumentos de autoridade, que visam a adquirir a eficácia de testemunho e limitar as derivas relativistas - as interpretações pouco referidas à estrutura mínima acordada ao real correm o risco de serem renegadas, caírem na opacidade ou no descrédito, a menos que sejam paulatinamente apropriadas pela sociedade.

Deve ser sublinhado que a retroação bomem-espaço (ROUX, 1999) subjacente ao pensamento figurativo é inerente tanto à paisagem geográfica quanto às paisagens ordinariamente percebidas e representadas. Uma vez os geógrafos pretendem compreender valores e significações espaciais construídos culturalmente sobre certas categorias, eles não poderão deixar de lado o poder semântico dos procedimentos mentais e lingüísticos de tipo metonímico, que fazem "saltar aos olhos" o que se vê e o que se quer fazer ver (partindo de e chegando a um certo repertório de antecipações socioculturais sempre em acomodação).

Não se pode exagerar, contudo, a abrangência e aplicabilidade da retórica metonímica como instrumento de análise geográfica; ela é apenas um indício dos processos cognitivos relacionados à paisagem. Como já disse Berdoulay (1988, p.2223), o discurso geográfico pode se tornar plenamente ideológico se concentrado no poder explicativo de certos conceitos. A simples enumeração de clichês relacionados a certos espaços tem pouca chance de ir além da reprodução do senso comum, sem chegar a compreender as razões de sua persistência. 
O que caracteriza a cultura é a dialética entre conformidade e ruptura, adaptabilidade e variabilidade, fundada numa praxis que pode ser concebida como a ação de persuadir ou convencer o outro através da palavra - definição mínima de retórica. À primeira vista, esta parece de fato resumirse a tanto, porém, talvez seja melhor pensá-la, junto com Meyer (1993, p.22), como "a negociação da distância entre os homens a propósito de uma questão, de um problema". A questão de definir o semi-árido ou o sertão, por ter um forte apelo identitário no Nordeste do Brasil, possibilitou comprovar amplamente o embate retórico presente nas descrições de paisagens pelos habitantes do interior de Pernambuco.

Trata-se, como se pode constatar a partir desta breve reflexão, de uma seara bastante complexa, mas que liberta definitivamente a retórica do único campo ao qual ela foi paulatinamente relegada: uma técnica fria e calculista a serviço do embuste, da enganação ou da ênfase vazia (donde o topos "tal argumento não passa de retórica"). Ora, não são essas acusações bastante similares às que se têm abatido de tempos em tempos sobre o conceito de paisagem? A introdução e renovação do papel da retórica paisagística contribui, portanto, para dar impulso ao debate na geografia cultural contemporânea.

\section{NOTAS}

1. Doutor em Geografia pela Universidade Federal do Rio de Janeiro (UFRJ). Professor Adjunto da Universidade Federal de Pernambuco (UFPE) camorim3@terra.com.br e caio.maciel@ufpe.br

\section{REFERÊNCIAS}

BERDOULAY, V. Des mots et des lieux. La dynamique du discours géographique. Paris:Éditions du CNRS, 1988.

CLAVAL, P. A geografia cultural. Florianópolis: Editora da UFSC, 1999.

CORRÊA, R. L.; ROSENDAHL, Z. (orgs.) Paisagem, tempo e cultura. Rio de Janeiro: Editora da UERJ, 1998.

DURAND, G. A imaginação simbólica. São Paulo: Cultrix, 1988.

GADAMER, H-G. Verdade e método. Traços fundamentais de uma hermenêutica filosófica. Petrópolis: Vozes, 1998.

GARDES-TAMINE, J. La rhétorique. Paris: Armand Colin, 1996.

LANDA, E. O preconceito como violência do pensamento: espaço narcísico e imagem do outro. In: FOOT HARDMAN F. (org.). Morte e Progresso. Cultura brasileira como apagamento de rastros. São Paulo: Fundação Editora da UNESP, 1998, p.71-79.

LUGER, G. F. Inteligência artificial: estruturas e estratégias para a solução de problemas complexos. Porto Alegre: Bookmann, 2004.

MACIEL, C. A. A. Metonímias Geográficas: imaginação e retórica da paisagem no semi-árido pernambucano. Tese (doutorado), UFRJ/CCMN, Geografia, 2004.

MEYER, M. Questions de rhétorique: langage, raison et séduction. Paris: Le Livre de Poche, 1993.

ROUX, M. Géograpbie et Complexité. Les espaces de la nostalgie. Paris: L'Harmattan, 1999. 


\section{ABSTRACT}

A DISCUSSION IS PRESENTED AS TO HOW THE CULTURAL APPROACH MAY ENVISAGE THE LANDSCAPE BOTH AS A SUBJECTIVE WORLD VIEW AND AS A REALITY WITH CONCRETE EXISTENCE. IN THIS WORK THE LANDSCAPE IS CONSIDERED AS PART OF THE DISCURSIVE PROCESS WHICH LINES ONE'S WORLD IMAGE UP STARTING FROM THE PROXIMATE ENVIRONMENT, SOMETHING CONCRETE AND PERCEIVABLE BY THE SENSES, BY MEANS OF CURRENT MENTAL STRUCTURES IN SOCIO-CULTURAL UNIVERSE OF COMMON PEOPLE. THUS, THINKING OF SPACE THROUGH THE LANDSCAPE MIGHT WELL ALLOW ONE AN ABSTRACT, NON-RANDOM JUMP FROM EXISTENCE'S CLOSE PLACES TO THE UNKNOWN. THIS HYPOTHESIS IS CALLED GEOGRAPHIC REPRESENTATIONAL INTRINSIC METONYMIC THINKING. IT MEANS THAT, ONCE AROUSED TO EXPRESS THEIR WAY OF INSERTION IN EVERY DAY LIFE IN BROADER SPATIAL EXPANSES, THE SUBJECTS WILL RESORT TO SOME SORT OF RETHORIC REASON IN ORDER TO COMMUNICATE LEISURELY WHATEVER THEY PERCEIVE AS MORE EVIDENT AND IMPORTANT IN THE LANDSCAPES. AS EXPERIMENTAL FIELD OF ANALYSIS A NUMBER OF LANDSCAPES AS PERCEIVED BY INHABITANTS OF THE SEMI-ARID REGION OF THE STATE OF PERNAMBUCO (BRAZIL) WERE INVESTIGATED, WITH A VIEW TO ESTIMATE THE EXPLANATORY POTENTIAL OF THE CONCEPT OF GEOGRAPHIC METONYMY. KEYWORDS - LANDSCAPE, LANDSCAPE RETHORIC, HERMENEUTICS, GEOGRAPHIC METONYMIES, BRAZIL'S SEMI-ARID BACK COUNTRY ("SERTÃO"). 